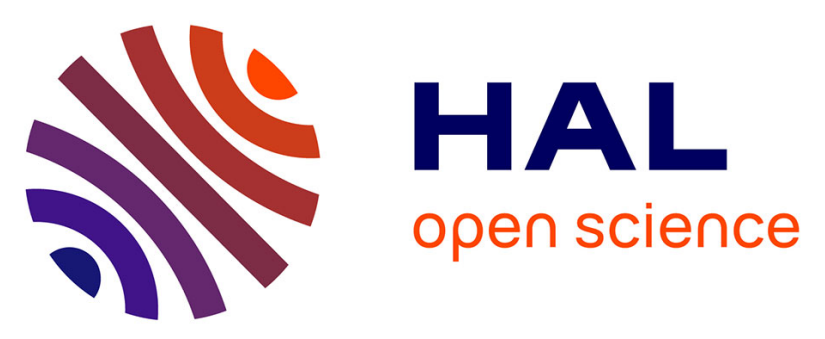

\title{
A wearable, low-power, health-monitoring instrumentation based on a programmable system-on-chip
}

Bertrand Massot, Claudine Géhin, Ronald Nocua, Andre Dittmar, Eric Mcadams

\section{To cite this version:}

Bertrand Massot, Claudine Géhin, Ronald Nocua, Andre Dittmar, Eric Mcadams. A wearable, lowpower, health-monitoring instrumentation based on a programmable system-on-chip. 2009 Annual International Conference of the IEEE Engineering in Medicine and Biology Society, Sep 2009, Minneapolis, United States. pp.4852-4855, 10.1109/IEMBS.2009.5332662 . hal-02361702

\section{HAL Id: hal-02361702 https://hal.science/hal-02361702}

Submitted on 13 Nov 2019

HAL is a multi-disciplinary open access archive for the deposit and dissemination of scientific research documents, whether they are published or not. The documents may come from teaching and research institutions in France or abroad, or from public or private research centers.
L'archive ouverte pluridisciplinaire HAL, est destinée au dépôt et à la diffusion de documents scientifiques de niveau recherche, publiés ou non, émanant des établissements d'enseignement et de recherche français ou étrangers, des laboratoires publics ou privés. 


\title{
A wearable, low-power, health-monitoring instrumentation based on a Programmable System-on-Chip ${ }^{\text {TM }}$
}

\author{
Bertrand Massot, Student Member, IEEE, Claudine Gehin, Member, IEEE, Ronald Nocua, Student Member, IEEE, \\ Andre Dittmar, Member, IEEE, and Eric McAdams, Senior Member, IEEE
}

\begin{abstract}
Improvement in quality and efficiency of health and medicine, at home and in hospital, has become of paramount importance. The solution of this problem would require the continuous monitoring of several key patient parameters, including the assessment of autonomic nervous system (ANS) activity using non-invasive sensors, providing information for emotional, sensorial, cognitive and physiological analysis of the patient. Recent advances in embedded systems, microelectronics, sensors and wireless networking enable the design of wearable systems capable of such advanced health monitoring.

The subject of this article is an ambulatory system comprising a small wrist device connected to several sensors for the detection of the autonomic nervous system activity. It affords monitoring of skin resistance, skin temperature and heart activity. It is also capable of recording the data on a removable media or sending it to computer via a wireless communication. The wrist device is based on a Programmable System-on-Chip (PSoC $^{\mathrm{TM}}$ ) from Cypress: PSoCs are mixed-signal arrays, with dynamic, configurable digital and analogical blocks and an 8-bit Microcontroller unit (MCU) core on a single chip. In this paper we present first of all the hardware and software architecture of the device, and then results obtained from initial experiments.

Index Terms-Ambulatory measurement, wireless sensors and systems, health monitoring, Programmable System-on-Chip (PSoC), autonomic nervous system (ANS).
\end{abstract}

\section{INTRODUCTION}

$\mathbf{H}$ EALTH monitoring already takes place in various settings: at home for prevention and in hospital for continuous assessment. It has become a pressing need for patients, to provide better quality of care, and also for society, to lead to more effective and lower cost health care provision. Unfortunately, ambulatory monitoring must overcome many constraints. These technical challenges include high integration for device size reduction, and low power consumption for extended patient autonomy. Each component has to be chosen according to these criteria, and PSoC is a preferential tool for reducing the number of components. Indeed, it can carry out all the steps from signal conditioning to transmission of formatted data, including analog to digital conversion and data processing, all within a single part component.

Manuscript created February 25, 2009;

B. Massot, C. Gehin, A. Dittmar and E. McAdams are with the Biomedical Sensors Group, Lyon Institute of Nanotechnology, UMR 5270 CNRS-INSA Lyon, Villeurbanne, France. bertrand.masssot@insalyon.fr, claudine.gehin@insa-lyon.fr, andre.dittmar@insa-lyon.fr, eric.mcadams@insa-lyon.fr

R. Nocua is with the AFIRM Group, TIMC-IMAG University Joseph Fourier, Grenoble, France. ronald.nocua@imag.fr

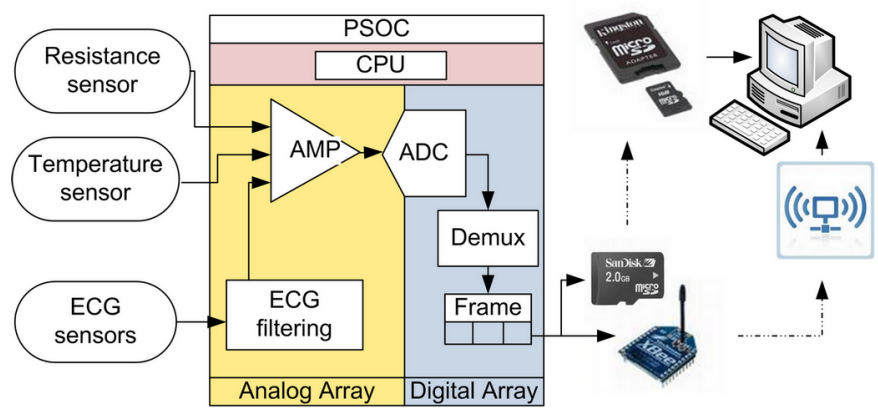

Fig. 1. System Architecture

Wireless communication is achieved by an $\mathrm{XBee}{ }^{\circledR} \mathrm{ZB} \mathrm{RF}$ module. This module meets the specifications necessary for wearable applications: with low power consumption, resulting from ZigBee Pro Feature Set and IEEE 802.15.4 compliance, it facilitates the implementation of short range wireless communications.

Embedded storage completes the ambulatory feature with the ability to record data on a micro-SD card, currently the smallest removable media with an acceptable storage capacity.

\section{Materials AND Methods}

\section{A. System Architecture}

System is mainly based on the PSoC. It is composed of an 8-bit Harvard architecture microprocessor (with a programmable frequency running in the present case at 12 $\mathrm{MHz}$ ), a programmable analog array and a programmable digital array (Fig. 1).

The analog blocks, based on configurable operational amplifier structures, perform sensor-interfacing and analog signal processing, especially for the ECG signal which requires a dedicated processing circuit. In addition, the analog array also includes a portion of the ADC, corresponding to the signal buffering.

The firmware, working on the MCU core, retrieves digitized values through the API functions of the ADC. It carries out additional treatment (averaging for resistance and temperature, and band-pass filtering for the ECG), before transmitting data to communication interfaces in the form of formatted data frames.

The digital blocks, based on configurable digital structures (timers, flip-flops, latches, etc.), are used to create timers 


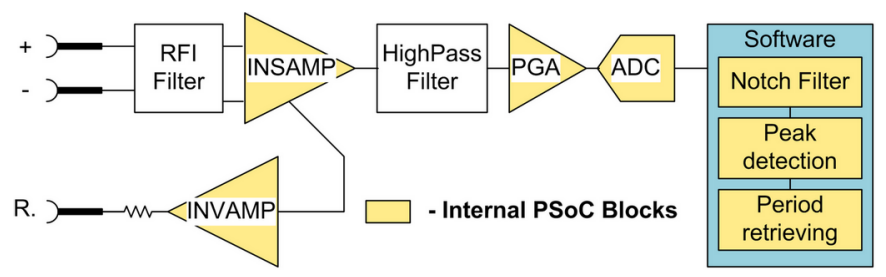

Fig. 2. Flowchart of Heart Rate measurement

(such as a millisecond clock) and communication interfaces: a SPI bus, to communicate with a micro Secure Digital flash card (micro SD), and UART to communicate with the XBee module.

Due to the limited number of analog blocks, PSoC limitations were reached with the impossibility of creating three parallel and independent acquisition chains (amplification, filtering, and analog to digital conversion). The solution was to multiplex analog signals in the signal processing chain. This is enabled by the possibilities of dynamic settings of analog functions (amplifier gains, entries routing, voltage references, etc.). There is therefore only one acquisition chain for the measurement of three physiological parameters, each analog block's parameters being reset in real time following the measurement progress. Demux is done after A/D conversion, so each signal can receive its own digital processing.

\section{B. Hardware Implementation}

The ECG signal (Fig. 2), from sensors in a 'Lead II' limb lead configuration (Fig. 3), passes through an RFI filter to the input of a high common-mode-rejection ratio (CMRR) instrumentation amplifier in order to eliminate noise. To improve noise immunity in an ambulatory context, a "Driven-Right-Leg" circuit [1] was implemented. From the output of the INSAMP, the signal passes through a high pass filter external to the PSoC (High Pass Filter). The reason for the use of discrete components for that filter is a result of the insufficient performance of PSoC filters when working at very low frequency (templates not respected, signal distortion from switch-capacitor blocks working at low frequency) [2]. Finally, the signal is once more buffered and amplified by a programmable gain amplifier (PGA) before being digitized by a 12-bit analog-to-digital converter

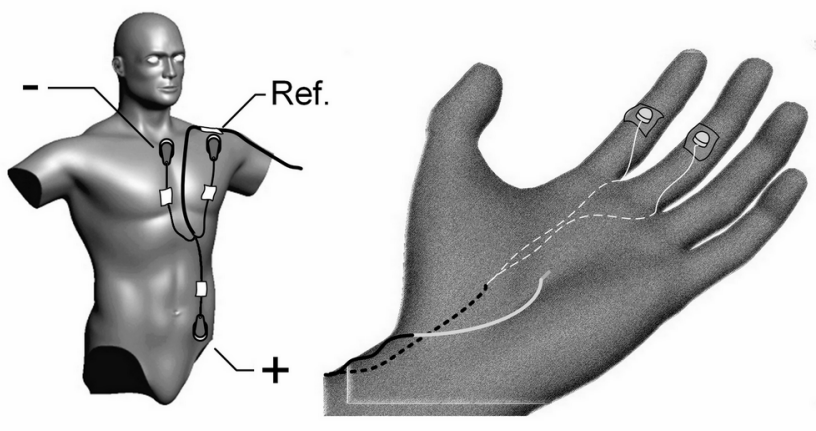

Fig. 3. Electrode positioning

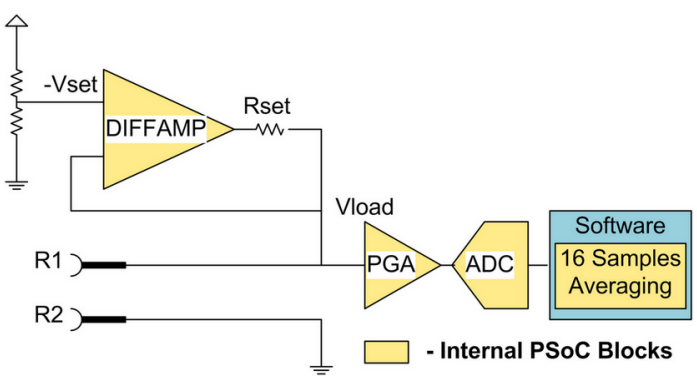

Fig. 4. Flowchart of EDR measurement

(ADC). The processing of the digitized data stream from the ADC is implemented in firmware and its description is made in part C. Software Description. It consists of a digital notch filter (second order IIR) to suppress $50 / 60 \mathrm{~Hz}$ line power noise, and a second order IIR bandpass filter $(5 \sim 16 \mathrm{~Hz})$. It detects R-peaks with an algorithm derived from the Tompkins' method [3], and a timer is used to count off the elapsed time from the previous R-peak. The electrodes used for obtaining the ECG were AMBU Blue Sensor T as recommended for stress tests.

Electrodermal responses (EDR) are obtained by measuring skin resistance (Fig. 4). We measure between to electrodes the potential difference resulting from constant current injection. Thus the measured voltage is an image of the skin resistance. According to Edelberg [4], an injected current less than $10 \mathrm{~A} . \mathrm{cm}^{-2}$ is optimal. We built a constant current source according to Dave Van Ess' description [5] from a differential amplifier (DIFFAMP) with a gain set to one, whose analog ground $V_{\text {ref }}$ is set to $A G N D=V D D / 2$. Then the voltage drop across the setting resistor $R_{\text {set }}$ is constant thus setting the current flowing through it. Assuming that the operational amplifiers are ideal, i.e. the input impedance is infinite and the output is an ideal voltage source, the current flowing through $R_{\text {set }}$ is the same as that through the skin resistance. With $V_{\text {set }}=-0.917 \mathrm{~V}, V_{\text {ref }}=1.650 \mathrm{~V}$ and $R_{\text {set }}=330 \mathrm{k} \Omega$, we obtain $I_{\text {set }}=2.13 \mu \mathrm{A}$. Electrodes used for measuring skin resistance are round $\mathrm{Ag} / \mathrm{AgCl}$ discs of $0.8 \mathrm{~cm}$ diameter (i.e. an area of $0.5=\mathrm{cm}^{2}$ ) resulting in a $4.24 \mu \mathrm{A} . \mathrm{cm}^{-2}$ current density, well within Edelberg's optimal range. A hydrogel pad was placed between the skin and the electrode in order to improve contact (avoiding variations in the area and quality of contact, and lowering contact impedance) and to avoid skin progressive moistening [6]. Electrodes were placed on the medial or distal phalanges of the index and middle fingers (Fig. 3), as these sites are characterized by pronounced electrodermal activity [7].

Skin temperature was measured using a BetaTHERM 10K3A1 thermistor (Fig. 5). Resistance changes were converted into voltages through a simplified Wheatstone bridge: The bias resistor was chosen in order to center voltage scale on $A G N D$ reference (i.e. $V D D / 2$ ). By selecting the same reference for the programmable gain amplifier (PGA), the 
second part of the bridge becomes unnecessary, thus reducing the number of discrete components.

\section{Software Description}

The firmware contains analog multiplexing control, digital filtering and digital communications. Analog multiplexing is controlled by means of the API of the analog input mux. Listing 1 is an example of the "on-the-fly" configuring process.

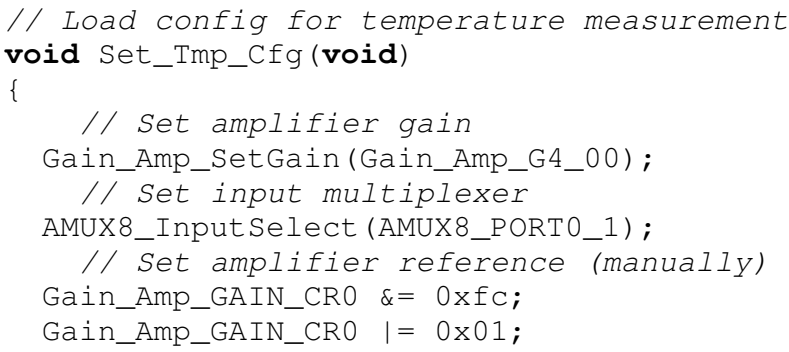

Listing 1. Analog Mux Example

Sample rate of the incremental ADC reaches 480 sps, so each signal is sampled at 160 sps and goes through digital filters. An example of these fast filters is shown on Listing 2, which is a $50 \mathrm{~Hz}$ Notch filter for ECG processing.

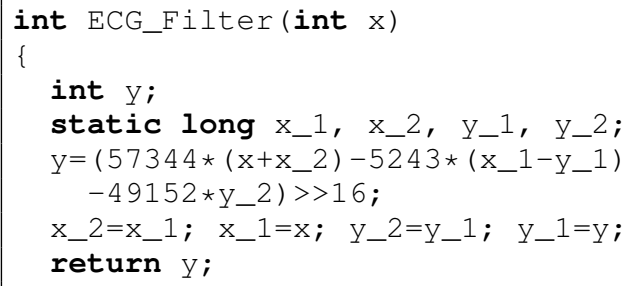

Listing 2. $50 \mathrm{~Hz} 2^{\text {nd }}$ Order IIR Notch Filter

Communication with the XBee module is made through an UART serial link with a rate of 57600 bauds, reading and writing being controlled by the UART API. An API also exists for SD-Card read/writing hence the communication with the micro-SD card is done with high level function calls. The clock for the SPI bus linked to the card is set at $4 \mathrm{MHz}$ and the read/write functions can reach a rate of 2250 Bytes.s ${ }^{-1}$.

\section{RESULTS}

Fig. 6 shows a comparison made between the system and a GSR Amp of ADInstrument (measuring skin resistance

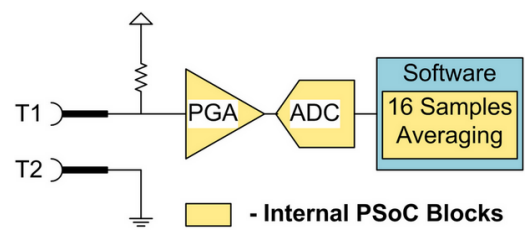

Fig. 5. Flowchart of skin temperature measurement
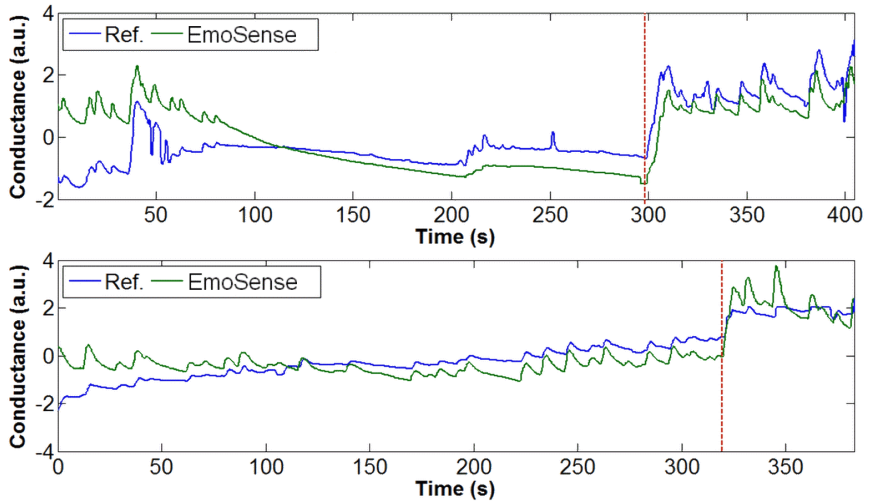

Fig. 6. Ambulatory and Ref. Instrumentation signals for skin resistance measurement

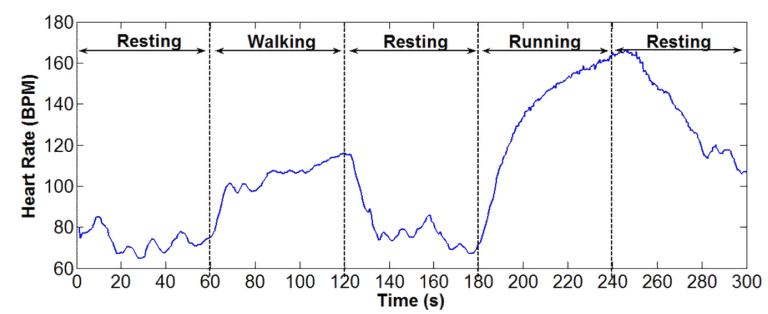

Fig. 7. Heart Rate signal during stress tests

with isolated alternating current). Six minutes tests were performed on two different subjects. An unexpected audio stimulus was applied after a five minute period of relaxation. Following signal standardization and trend removing (the electrodes used with the ADInstrument are only recommended for very short measurements), correlation between the signals was 0.75 , showing the ambulatory system's ability to match an immovable instrumentation in terms of performance.

Robustness of heart rate measurement was tested on an ECG measurement during several periods of patient effort (walking and sprinting). The ECG remained stable even when the subject ran and the excessive movements generated considerable signal noise. The peak detection algorithm recovered the full R-R intervals from the ECG (see traces on Fig. 7).

Table I shows current consumption under different operating modes, with a power voltage of $3.3 \mathrm{~V}$. As the system is used with a $2200 m A h$ battery placed in the bracelet, it can afford four day of continuous monitoring without recharging the battery, enabling long-term measurement to be carried out.

\section{Discussion}

Heart rate variability (HRV) [8] and skin resistance responses (SRR) [7] are the main indicators for the noninvasive emotional analysis. Although skin resistance is indicative of emotional, sensorial and cognitive stimuli, this response is also affected by thermoregulation in extreme conditions. This example demonstrates the need of also retrieving information concerning the subject's environment: 
TABLE I

TYPICAL CURRENT CONSUMPTION

\begin{tabular}{c||c}
\hline Operating Modes & Current \\
\hline \hline SD inactive / Wireless inactive & $10 \mathrm{~mA}$ \\
\hline SD active / Wireless inactive & $15 \mathrm{~mA}$ \\
\hline SD inactive / Wireless active & $23 \mathrm{~mA}$ \\
\hline SD active / Wireless active & $28 \mathrm{~mA}$ \\
\hline
\end{tabular}
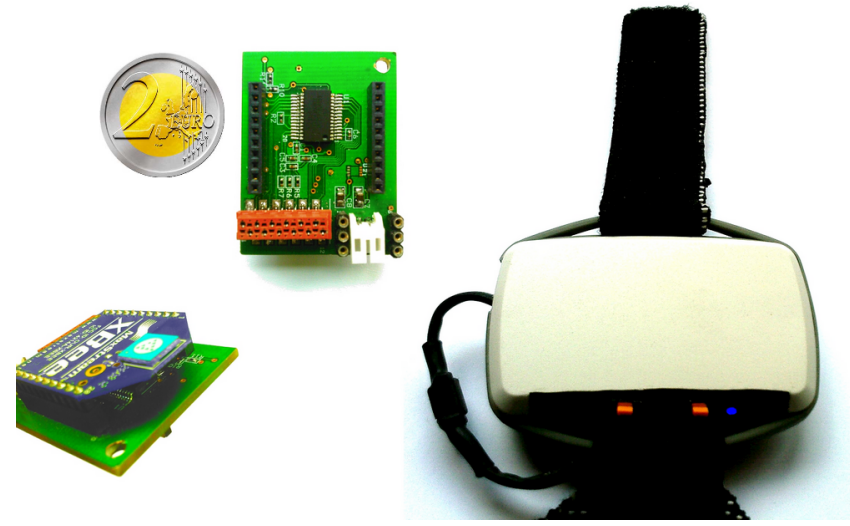

Fig. 8. Wrist-device preview

skin temperature provides information on vasoconstriction and is also representative of the environmental temperature [9]. The above three signals therefore need continuous monitoring and this has been achieved with the presented device. Furthermore, ZigBee mesh topologies enable the device to be integrated into a Wireless Wearable Body Area Network (WWBAN) as a wireless multi-sensor in a telemedicine system [10].

\section{CONCLUSION}

This research involved the development of wearable and ambulatory monitoring systems [11][12]. The ambulatory aspect of the device leads to a wide range of applications:

- In the study of vigilance when driving, where signals can be interpreted in real-time [13]

- During continuous monitoring under extreme conditions (firemen)

- In the study of sports performance

- For health monitoring at home, with a telemedicine system
The future of the project is to develop an intelligent system capable of providing alarms in various situations (stress, vigilance, critical states). We are working on offline algorithms for the extraction of new relevant indicators in order to quantify autonomic nervous system activity. These indicators should have low CPU consumption in order to be embedded on a PSoC architecture device for real-time detection.

\section{REFERENCES}

[1] B. B. Winter and J. G. Webster, "Driven-right-leg circuit design," IEEE Trans. Biomed. Eng., no. 1, pp. 62-66, Jan. 1983.

[2] D. Van Ess. (2004) Understanding switched capacitor filters. [Online]. Available: http://www.psocdeveloper.com/

[3] J. Pan and W. J. Tompkins, "A real-time qrs detection algorithm," IEEE Trans. Biomed. Eng., no. 3, pp. 230-236, March 1985.

[4] R. Edelberg, Methods in psychophysiology. C. C. Brown, 1967, ch. Electrical properties of the skin, pp. 1-53.

[5] D. Van Ess. (2002) Programmable bipolar analog current source. [Online]. Available: http://www.psocdeveloper.com/

[6] E. T. McAdams, Encyclopedia of Medical Devices and Instrumentation. J. G. Webster, 2002, ch. Bioelectrodes, pp. 120-166.

[7] W. Boucsein, Electrodermal Activity. Plenum Press, New York, 1992

[8] "Heart rate variability: standards of measurement, physiological interpretation and clinical use. task force of the european society of cardiology and the north american society of pacing and electrophysiology." Circulation, vol. 93, no. 5, pp. 1043-1065, Mar 1996.

[9] C. Collet, E. Vernet-Maury, G. Delhomme, and A. Dittmar, "Autonomic nervous system response patterns specificity to basic emotions,' J. Auton. Nerv. Syst., vol. 62, no. 1-2, pp. 45 - 57, 1997. [Online]. Available: http://www.sciencedirect.com/science/article/B6T053YTCC8H-N/2/06106094dd9a46d6881b6bea38dcfe7c

[10] E. Jovanov, A. Milenkovic, C. Otto, P. De Groen, B. Johnson, S. Warren, and G. Taibi, "A wban system for ambulatory monitoring of physical activity and health status: Applications and challenges," in Proc. 27th Annual International Conference of the Engineering in Medicine and Biology Society IEEE-EMBS 2005, 17-18 Jan. 2006 , pp. 3810-3813.

[11] F. Axisa, C. Gehin, G. Delhomme, C. Collet, O. Robin, and A. Dittmar, "Wrist ambulatory monitoring system and smart glove for real time emotional, sensorial and physiological analysis," in Proc. 26th Annual International Conference of the IEEE Engineering in Medicine and Biology Society IEMBS '04, vol. 1, 1-5 Sept. 2004, pp. 2161-2164.

[12] A. Dittmar, R. Meffre, F. De Oliveira, C. Gehin, and G. Delhomme, "Wearable medical devices using textile and flexible technologies for ambulatory monitoring," in Proc. 27th Annual International Conference of the Engineering in Medicine and Biology Society IEEE-EMBS 2005, 2005, pp. 7161-7164.

[13] C. Ramon, A. Clarion, C. Gehin, C. Petit, C. Collet, and A. Dittmar, "An integrated platform to assess driver's physiological and functional states," in Proc. 30th Annual International Conference of the IEEE Engineering in Medicine and Biology Society EMBS 2008, 20-25 Aug. 2008, pp. 506-509. 